\title{
EFEK SERETAN KERANGKA INERSIAL DI DALAM MEDAN BINTANG NEUTRON YANG BEROTASI DAN STASIONER
}

\author{
Tika Restianingsih $^{1^{*}}$, Muhammad Farchani Rosyid ${ }^{2}$ \\ ${ }^{1}$ Prodi Fisika, Fakultas Sains dan Teknologi, Universitas Jambi, Mendalo Indah, Jambi, 36361, Indonesia \\ ${ }^{2}$ Departemen Fisika, Fakultas Matematika dan Pengetahuan Alam, Universitas Gadjah Mada, Yogyakarta, 55281 Indonesia \\ *e-mail: tika.restianingsih@unja.ac.id
}

\begin{abstract}
ABSTRAK
Telah dilakukan kajian tentang efek seretan kerangka inersial di dalam bintang neutron. Efek seretan kerangka inersial (efek Lense Thirring) telah diprediksi menggunakan teori relativitas umum pada tahun 1918. Ketika bintang neutron berotasi cepat, maka ruang waktu disekitarnya juga ikut terseret searah dengan arah rotasi bintang. Efek seretan kerangka cukup kecil dan akan terlihat jelas pada bintang-bintang antap seperti bintang neutron. Selanjutnya, dirumuskan laju presesi seretan kerangka inersial $\left(\Omega_{L T}\right)$ di dalam bintang neutron yang berotasi, stasioner, dan simetri sumbu. Nilai $\Omega_{L T}$ akan mengecil dari pusat bintang ke permukaan. Efek seretan kerangka inersial berbanding terbalik dengan jari-jari bintang dan sebanding dengan kecepatan rotasi bintang.
\end{abstract}

Kata Kunci: Bintang Neutron; Medan Stasioner; Efek Lense Thirring; Relativitas Umum.

\section{ABSTRACT}

[Title: Inertial Frame Dragging Effect Inside The Rotating and Stationary Neutron Star's Field] The inertial frame dragging effect of rotating neutron star has been studied. Inertial frame dragging effect, also well known as Lense Thirring effect, has been predicted using general theory of relativity in 1918. When the neutron star rotates very quickly, the space time around it will be dragged to the direction of the rotation. The Lense Thirring effect is small enough for small objects so it will be clearly seen for massive objects like compact stars, especially neutron star. Later, we derive the equation of frame dragging rate $\left(\Omega_{L T}\right)$ inside the rotating neutron star, which is axisymmetrik and stationary. Frame dragging rate is decreasing from the center to the surface of stars. It is also noted that $\Omega_{L T}$ is proportional to the angular velocity of star.

Keywords: Neutron Star; Stationary Field; Lense Thirring Effect; General Relativity.

\section{PENDAHULUAN}

Semua bintang di alam semesta pada akhirnya akan kehabisan bahan bakar dan mati melalui ledakan supernova hingga menyisakan suatu benda yang dikenal sebagai bintang antap (compact stars). Bintang antap adalah benda paling antap yang dapat ditemukan di alam semesta dan terdiri dari tiga jenis, yaitu bintang neutron, katai putih, dan lubang hitam. Bintang neutron sendiri adalah bintang antap yang memiliki massa $1,4 M_{\odot}<M<$ $3 M_{\odot}$, dengan $M_{\odot}$ merupakan massa matahari dan jari-jarinya hanya sekitar $12 \mathrm{~km}$ (Shapiro, 2004).

Gagasan tentang bintang neutron pertama kali diusulkan oleh Baade dan Zwicky pada tahun 1934. Ledakan supernova dapat mengubah bintang biasa menjadi bintang neutron, suatu bintang dengan kerapatan sangat tinggi dan disusun oleh neutron, sering disebut sebagai inti atom raksasa (Arny, 2014). Lalu pada tahun 1939, Tolman, Openheimer, dan Volkof menurunkan persamaan kesetimbangan hidrostatik untuk bintang bersimetri bola dalam kerangka kerja relativitas umum. Penelitian tentang bintang neutron secara teoretik terus berlanjut hingga terbukti keberadaannya setelah pengamatan pulsar (pulsating star) oleh Jocelyn Bell pada tahun 1967 (Haensel dkk, 2007).

Seperti halnya bintang biasa, bintang neutron juga berotasi. Rotasi bintang neutron menghasilkan gaya sentrifugal yang sangat besar dan menyebabkan bentuk bintang neutron yang tidak bulat sempurna. Ketika inti bintang biasa meluruh menjadi bintang neutron, kelestarian momentum sudut mengakibatkan meningkatnya rotasi bintang (Glendenning, 2000). 
Rotasi suatu benda dapat mempengaruhi ruang waktu di sekitarnya yang dikenal dengan efek seretan kerangka. Efek seretan kerangka merupakan efek penting dalam relativitas umum dan diusulkan pertama kali oleh Lense dan Thirring sehingga sering disebut sebagai efek Lense-Thirring (LT). Setiap giroskop uji pada ruang waktu di sekitar benda berotasi akan mendekati frekuensi seretan kerangka yang sebanding dengan momentum sudut dan kekompakan (keantapan) benda yang berotasi (Lense dan Thirring, 1918).

Perhitungan secara teoretik untuk menentukan laju seretan kerangka inersial (LT) di dalam bintang neutron yang berotasi lambat di berikan oleh Hartle dan diamati bahwa frekuensi seretan kerangka lebih tinggi di pusat dibandingkan di permukaan bintang (Hartle, 1967). Frekuensi seretan kerangka tidak akan pernah melebihi frekuensi rotasi bintang neutron. Hartle mempelajari efek ini pada keseimbangan struktur bintang neutron yang berotasi lambat (Hartle dan Thorne, 1968). Efek seretan kerangka pada frekuensi Kepler diteliti oleh Glendenning dan Weber (Glendenning dan Weber, 1994).

Selanjutnya, Morsink dan Stella mempelajari peran efek seretan kerangka dalam menjelaskan quasi periodik osilasi akresi bintang neutron. Morsink dan Stella memperkirakan frekuensi presesi $v_{p}$ dari bidang orbit cakram di sekitar sumbu simetri bintang sebagai selisih antara frekuensi osilasi parikel sepanjang longitude dan latitude yang diamati pada jarak tak hingga. Perhitungan tersebut memperkenalkan zero angular momentum observer (ZAMO) (Morsink, dkk., 1999).

Perhitungan Hartle juga menjelaskan cara efek seretan yang mempengaruhi momen inersial pada bintang neutron yang berotasi (Weber, dkk., 2006). Analisa untuk laju presesi Lense Thirring pada pendekatan medan lemah diberikan dalam persamaan $\overrightarrow{\Omega_{L T}}=\frac{1}{r^{3}}(3(\vec{J} \cdot \hat{r}) \hat{r}-\vec{J})$, dengan $\hat{r}$ adalah vector satuan sepanjang arah $r$ (Iorio, 2011). Melalui persamaan tersebut, juga dapat dihitung efek seretan kerangka inersial untuk galaksi dengan pusat galaksi adalah lubang hitam (Hackmann dan Lammerzahl, 2012).

Laju presesi LT pada ruang waktu stasioner yang sangat melengkung juga telah didiskusikan secara rinci oleh Chakraborty dan Majumdar (Chakraborty dan Majumdar, 2014). Perhitungan dan hasil secara eksak mengenai efek seretan kerangka di dalam bintang neutron untuk berbagai model persamaan keadaan bintang neutron telah dijelaskan oleh Chakraborty. Laju seretan kerangka inersial di dalam bintang neutron akan mengecil dari pusat bintang menuju kutub bintang. Sedangkan untuk daerah ekuator, laju seretan kerangka mengecil dari pusat bintang menuju daerah tepat sebelum permukaan ekuator, lalu naik lagi sampai permukaan ekuator (Chakraborty $d k k, 2014$ ).

\section{HASIL DAN PEMBAHASAN}

Bintang neutron lahir ketika terjadi ledakan supernova setelah bintang sebelumnya (presupernova) kehabisan bahan bakar inti di pusatnya. Inti mengalami keruntuhan gravitasi menjadi bintang neutron (atau lubang hitam) sedangkan bagian luar lapisan pre-supernova terlempar keluar oleh adanya gelombang kejut (shock wave). Setelah tejadinya supernova, bintang neutron mempertahankan hukum kelestarian momentum anguler dan hukum kelestarian fluks magnetik sehingga memiliki kecepatan anguler yang tinggi dan medan magnet yang kuat (Glendenning, 2000).

Bintang neutron merupakan salah satu benda relativistik. Efek relativistik ditentukan oleh parameter kekompakan, yaitu $x_{G R}=r_{S} / R$, dengan $r_{S}$ adalah jari-jari jari-jari Schwarzschild. Bintang neutron memiliki $x_{G R}=0,2-0,4$.

Pembuktian keberadaan bintang neutron diawali dengan penemuan pulsar. Pulsar (pulsating star) merupakan bintang neutron yang berotasi dan menghasilkan pancaran pulsa. Pembentukan pulsar diawali ketika inti bintang massive runtuh menjadi bintang neutron setelah terjadinya supernova. Berdasarkan hukum kelestarian momentum sudut dan kelestarian fluks magnetik, semakin kecil jarijari maka kecepatan sudut dan medan magnet akan semakin besar. Dengan demikian, bintang neutron dikenal sebagai bintang dengan kecepatan rotasi dan medan magnet yang cukup besar (Haensel $d k k$, 2007).

Efek seretan kerangka (Lense-Thirring effect) merupakan efek dalam ruang waktu yang diprediksi dengan teori gravitasi Einstein (relativitas umum), yaitu efek ketika kerangka inersial lokal di dalam atau di sekitar benda yang berotasi ikut terseret dengan arah seretannya searah rotasi benda. Efek ini sangat kecil dan akan terlihat semakin jelas untuk benda bermassa sangat besar, salah satunya bintang neutron. Pada penelitian ini, bintang neutron yang ditinjau adalah bintang neutron yang stasioner dan ber-simetri sumbu.

Medan gravitasi dikatakan stasioner jika ada suatu koordinat $x^{\mu}$ dengan komponen-komponen 
dari tensor metrik $g_{\mu \nu}$ tak bergantung waktu $t=x^{0}$. Definisi ini dapat diperjelas dengan menggunakan sifat instrinsik dari ruang waktu $(M, g)$. Jika $K$ adalah suatu medan vektor, maka ditulis

$$
K=K^{\mu} \frac{\partial}{\partial x^{\mu}}, \text { dengan } K^{\mu}=\delta_{0}^{\mu} .
$$

$K^{\mu}$ merupakan komponen-komponen dari medan vektor $K$ dan $\partial / \partial x^{\mu}$ adalah basis dari medan vektor K.m

Pada teori keragaman (manifold), ruang waktu stasioner adalah ketika ada medan Killing $K$ sedemikian rupa sehingga turunan Lie dari medan vektor $K$ terhadap metrik $g$ adalah nol,

$$
\left(L_{K} g\right)_{\mu \nu}=K^{\lambda} g_{\mu \nu, \lambda}+g_{\lambda \nu} K_{, \mu}^{\lambda}+g_{\mu \lambda} K_{, v}^{\lambda}=0 \text {. }
$$

Medan $K$ ditulis $K=\frac{\partial}{\partial x^{0}}$ dan disebut sebagai isometrik infinitesimal.

Medan statik merupakan kasus khusus dari medan stasioner. Jika dipilih suatu koordinat ruang dengan metrik $g_{0 i}=0(i=1,2,3)$, maka medan Killing orthogonal terhadap tampang lintang ruang ( $t=$ tetap). Forma-1 $\omega$ merupakan dual vektor dari medan $K$ dan memenuhi

$\omega=\omega_{\mu} d x^{\mu}=g_{\mu \nu} K^{\nu} d x^{\mu}=g_{00} d x^{0}$.

Hal ini berarti setiap pengamat yang bergerak bersama aliran medan Killing $K$ tidak mengalami perubahan (Strauman, 2004). Medan vektor $K$ adalah medan Killing dan komponen tidak nol hanyalah $K^{0}$. Pada ruang waktu, $d x^{0}=d t$ sehingga

$$
\omega=g_{00} d t=\langle K, K\rangle d t .
$$

Pada koordinat bak waktu, diketahui $K=$ $\frac{\partial}{\partial t}=\partial_{t}$ dan $g_{0 i}=\left\langle\partial_{t}, \partial_{i}\right\rangle=\left\langle K, \partial_{i}\right\rangle=0$. Jika kondisi Frobenius, $\omega \wedge d \omega=0$ suatu medan Killing bak waktu $K$ terpenuhi, maka secara lokal metrik $g$ dapat ditulis sebagai berikut

$g=g_{00}(x) d t^{2}+g_{i k}(x) d x^{i} d x^{k}$,

dan

$g_{00}=\langle K, K\rangle$.

Seorang pengamat dalam keadaan diam pada ruang waktu stasioner dengan medan Killing bak waktu $K$, maka pengamat tersebut akan bergerak sepanjang kurva integral $\gamma(\tau)$. Kecepatan4 pengamat tersebut adalah $u=(-\langle K, K\rangle)^{-1 / 2} K$

Kemudian dipilih suatu triad ortonormal $\left\{e_{i}\right\}$ sepanjang kurva $\gamma$ yang memenuhi transport Lie $L_{K} e_{i}=0$, dengan $i=1,2,3$. Oleh karena itu, $e_{i}$ akan tegak lurus terhadap medan $K$ dan $u$. Triad $\left\{e_{i}\right\}$ dapat dikatakan sebagai sumbu pada keadaan diam yang didefinisikan sebagai "kerangka Copernican" seperti dapat dilihat pada gambar 1 .

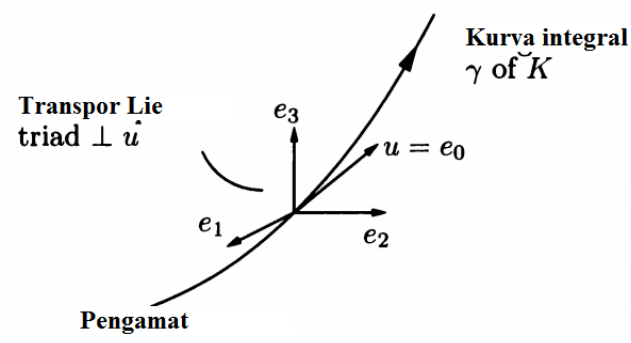

Gambar 1. Presesi spin dalam medan stasioner relatif terhadap pengamat Copernican (Strauman, 2004).

Rotasi spin terhadap sistem Copernican diberikan oleh persamaan

$\Omega=\frac{1}{2}\langle K, K\rangle^{-1} *(\boldsymbol{K} \wedge d \boldsymbol{K})$,

dengan $*(\boldsymbol{K} \wedge d \boldsymbol{K})$ dan $\Omega$ merupakan forma-1. Untuk menyelesaikan persamaan (8), perlu dilakukan penjabaran terhadap medan $K$. Pada medan stasioner berdimensi empat, metrik $g_{\mu \nu}$ tidak bergantung pada $t=x^{0}$, maka

$\boldsymbol{K}=g_{00} d t+g_{0 i} d x^{i}$

$d \boldsymbol{K}=g_{00, k} d x^{k} \wedge d t+g_{0 i, k} d x^{k} \wedge d x^{i}$,

$\boldsymbol{K} \wedge d \boldsymbol{K}=\left(g_{00} d t \wedge g_{00, k} d x^{k} \wedge d t\right)+$ $\left(g_{00} d t \wedge g_{0 i, k} d x^{k} \wedge d x^{i}\right)+\left(g_{0 i} d x^{i} \wedge\right.$ $\left.g_{00, k} d x^{k} \wedge d t\right)+\left(g_{0 i} d x^{i} \wedge g_{0 i, k} d x^{k} \wedge\right.$ $\left.d x^{i}\right)=\left(g_{00} g_{0 i, j}-g_{0 i} g_{00, j}\right) d t \wedge d x^{j} \wedge$ $d x^{i}+g_{0 k} g_{0 i, j} d x^{k} \wedge d x^{j} \wedge d x^{i}$.

dengan $\quad g_{i j, k}=\frac{\partial g_{i j}}{\partial x^{k}}$ merupakan wakilan untuk turunan parsial terhadap koordinat $x^{\mu}$.

Selanjutnya, digunakan operasi bintang Hodge diperoleh 


$$
\begin{aligned}
& *(\boldsymbol{K} \wedge d \boldsymbol{K})=\frac{g_{00}}{\sqrt{-g}} \epsilon_{i j l}\left(\frac{g_{0 i}}{g_{00}}\right)_{, j}\left[\left(g_{i k} d x^{k}+\right.\right. \\
& \left.g_{l 0} d x^{0}\right)-\left(g_{l 0} d x^{0}+\frac{g_{l 0} g_{k 0}}{g_{00}} d x^{k}\right.
\end{aligned}
$$

Maka laju presesi benda dalam medan stasioner relative terhadap pengamat Copernican menurut persamaan (8) dinyatakan sebagai berikut

$$
\Omega=\frac{g_{00}}{2 \sqrt{-g}} \epsilon_{i j l}\left(\frac{g_{0 i}}{g_{00}}\right)_{, j}\left(\partial_{k}-\frac{g_{k 0}}{g_{00}} \partial_{0}\right)
$$

Efek seretan kerangka atau lebih dikenal sebagai efek Lense Thirring merupakan efek ketika suatu partikel jatuh menuju benda yang berotasi, maka partikel akan tertarik dengan arah tarikannya searah rotasi benda tersebut. Efek ini sebanding dengan kecepatan rotasi suatu benda. Sedangkan rotasi benda juga dipengaruhi oleh massa dan jari-jari benda tersebut. Pada bintang neutron tunggal (terisolasi), kecepatan rotasinya cukup kuat karena tidak ada pengaruh gravitsi dari benda disekitarnya.

Bintang neutron yang berotasi, stasioner, dan simetri sumbu, bentuk umum elemen garis menurut Komatsu-Eriguchi-Hachisu (KEH) adalah sebagai berikut

$$
\begin{aligned}
d s^{2} & =-e^{\gamma+\sigma} d t^{2}+e^{2 \alpha}\left(d r^{2}+r^{2} d \theta^{2}\right) \\
& +e^{\gamma-\sigma} r^{2} \sin ^{2} \theta(d \phi-\omega d t)^{2},
\end{aligned}
$$

dengan $\gamma, \sigma, \alpha$, dan $\omega$ adalah sembarang fungsi yang hanya bergantung pada $r$ dan $\theta$. $\omega$ merupakan kecepatan rotasi dari bintang neutron (Komatsu, $d k k, 1989)$. Pada artikel ini digunakan satuan alamiah $(G=c=1)$. Dengan demikian, elemen-elemen metrik $g_{\mu \nu}$ ditulis sebagai berikut

$$
\begin{gathered}
g_{\mu \nu}= \\
\left(\begin{array}{cccc}
\omega^{2} e^{\gamma-\sigma} r^{2} \sin ^{2} \theta-e^{\gamma+\sigma} & 0 & 0 & -\omega e^{\gamma-\sigma} r^{2} \sin ^{2} \theta \\
0 & e^{2 \alpha} & 0 & 0 \\
0 & 0 & e^{2 \alpha} r^{2} & 0 \\
-\omega e^{\gamma-\sigma} r^{2} \sin ^{2} \theta & 0 & 0 & e^{\gamma-\sigma} r^{2} \sin ^{2} \theta
\end{array}\right)
\end{gathered}
$$

Selanjutnya, jika dianggap bahwa materi di dalam bintang neutron adalah fluida sempurna dengan rapat energy $\epsilon=\rho_{0}+\rho_{i}$, maka persamaan tensor energi-momentumnya adalah

$T^{\mu \nu}=\left(\rho_{0}+\rho_{i}+p\right) u^{\mu} u^{\nu}+p g^{\mu \nu}$ dengan $\rho_{0}$ adalah rapat energi diam, $\rho_{i}$ adalah rapat energi dalam, $p$ adalah tekanan, dan $u^{\mu}$ adalah kecepatan-4 yang didefinisikan pada persamaan (7).

Utuk mencari laju presesi seretan kerangka inersial (frekuensi presesi Lense Thirring ) pada bintang neutron, digunakan persamaan (13) dengan menganggap pengamat dalam keadaan diam (pengamat Copernican). Frekuensi presesi Lense Thirring $\left(\Omega_{L T}\right)$ merupakan kecepatan sudut partikel ketika memasuki bintang neutron dan ketika bintang berada dalam medan stasioner. Pada ruang waktu stasioner dan simetri sumbu, komponen metrik yang tidak nol hanyalah $g_{0 i}=g_{0 \phi}, i=\phi$ dan $j, l=r, \theta$. Dengan demikian, persamaan menjadi

$$
\begin{aligned}
& \Omega_{L T}=\frac{1}{2 \sqrt{g}}\left[\left(g_{0 \phi, r}-\frac{g_{0 \phi}}{g_{00}} g_{00, r}\right) \partial_{\theta}-\right. \\
& \left.\left(g_{0 \phi, \theta}-\frac{g_{0 \phi}}{g_{00}} g_{00, \theta}\right) \partial_{r}\right],
\end{aligned}
$$

Kemudian $\Omega_{L T}$ diubah ke dalam bentuk basis ortonormal, atau dinyatakan dalam bentuk vektor pada arah $\hat{r}$ dan $\hat{\theta}$ sebagai berikut

$$
\begin{aligned}
& \vec{\Omega}_{L T}=\frac{1}{2 \sqrt{g}}\left[\sqrt{g_{r r}}\left(g_{0 \phi, \theta}-\frac{g_{0 \phi}}{g_{00}} g_{00, \theta}\right) \hat{r}+\right. \\
& \left.\sqrt{g_{\theta \theta}}\left(g_{0 \phi, r}-\frac{g_{0 \phi}}{g_{00}} g_{00, r}\right) \hat{\theta}\right]
\end{aligned}
$$

Setelah mendapatkan persamaan (18), kemudian akan didapatkan Kecepatan sudut presesi LT di dalam bintang neutron menggunakan komponenkomponen metrik pada persamaan (15) diantaranya

$$
\begin{aligned}
& g_{r r}=e^{2 \alpha}, \\
& g_{0 \phi}=-\omega e^{\gamma-\sigma} r^{2} \sin ^{2} \theta, \\
& g_{00}=\omega^{2} e^{\gamma-\sigma} r^{2} \sin ^{2} \theta-e^{\gamma+\sigma}, \\
& g_{\theta \theta}=e^{2 \alpha} r^{2} .
\end{aligned}
$$

Selanjutnya, dengan memasukkan komponen-komponen metrik ke persamaan (18), maka diperoleh seretan kerangka inersial di dalam bintang neutron yang berotasi sebagai berikut

$$
\begin{aligned}
& \vec{\Omega}_{L T}=\frac{e^{-(\alpha+\sigma)}}{2\left(\omega^{2} r^{2} \sin ^{2} \theta-e^{2 \sigma}\right)}\left[\left(\omega^{2} \omega_{, \theta} r^{2} \sin ^{3} \theta+\right.\right. \\
& \left.e^{2 \sigma}\left(\omega_{, \theta} \sin \theta+2 \omega \cos \theta-2 \sigma_{, \theta} \omega \sin \theta\right)\right) \hat{r}+ \\
& \sin \theta\left(\omega^{2} \omega_{, r} r^{3} \sin ^{2} \theta+e^{2 \sigma}\left(2 \omega+r \omega_{, r}-\right.\right. \\
& \left.\left.\left.2 \omega r \sigma_{, r}\right)\right) \hat{\theta}\right] .
\end{aligned}
$$


Sedangkan besar laju seretan kerangka inersial di dalam bintang neutron adalah dengan mencari besar dari vektor pada persamaan (19)

$\Omega_{L T}=\frac{e^{-(\alpha+\sigma)}}{2\left(\omega^{2} r^{2} \sin ^{2} \theta-e^{2 \sigma}\right)}\left[\left[\omega^{2} \omega_{, \theta} r^{2} \sin ^{3} \theta+\right.\right.$ $\left.e^{2 \sigma}\left(\omega, \theta \sin \theta+2 \omega \cos \theta-2 \sigma_{, \theta} \omega \sin \theta\right)\right]^{2}+$ $\sin ^{2} \theta\left[\omega^{2} \omega_{, r} r^{3} \sin ^{2} \theta+e^{2 \sigma}\left(2 \omega+r \omega_{, r}-\right.\right.$ $\left.\left.\left.2 \omega r \sigma_{, r}\right)\right]^{2}\right]^{1 / 2}$.

Untuk mengetahui besarnya laju seretan kerangka di pusat bintang neutron, maka tinjau $r=$ 0 pada persamaan (20) diperoleh

$\Omega_{L T}=\omega e^{-(\alpha+\sigma)}$

dengan $\omega_{, \theta}=\sigma_{, \theta}=0$ karena pada pusat bintang tidak bergantung pada sudut $\theta$.

Berdasarkan persamaan (20) dan (21) maka diketahui bahwa semakin kecil jari-jari atau semakin mendekat ke pusat bintang, efek seretan kerangka semakin besar. Sebaliknya, efek akan mengecil ketika $r$ semakin membesar, dan akan tidak ada ketika berada pada jarak yang sangat jauh dari bintang (ruang menjadi datar).

Hal ini sesuai dengan prediksi Einstein dalam teori relativitas umum. Suatu benda dengan massa yang sangat besar akan mempengaruhi ruang waktu disekelilingnya. Pengaruh tersebut ditunjukkan dengan nilai kelengkungan yang besar. Ketika benda masif tersebut berotasi, maka ruang waktu disekitarnya juga akan ikut berotasi (terseret) ke arah rotasi benda.

Untuk lebih mudah memahaminya, dapat dianalogikan dengan suatu bola pejal yang diletakkan diatas kain. Semakin besar massa bola, maka semakin melengkung kain yang ditimpa bola tersebut. Kemudian ketika bola diputar atau dirotasikan, maka kain disekitarnya juga akan berkerut ke arah rotasi bola. Pada analogi ini, bola merupakan benda bermassa besar (misal: bintang neutron) dan kain adalah ruang waktu. Melalui analogi ini, maka dapat diketahui bahwa untuk bagian kain yang jauh dari bola akan sedikit efek kerutannya dibandingkan dengan wilayah kain yang dekat dengan bola. Hal ini sesuai dengan yang diungkapkan dalam persamaan (20) untuk benda masif di dalam ruang waktu.

\section{KESIMPULAN}

1. Rotasi bintang neutron dapat mempengaruhi ruang waktu di sekitarnya yang disebut sebagai efek seretan kerangka inersial (efek Lense Thirring).

Ketika suatu partikel dijatuhkan ke dalam bintang neutron yang berotasi, maka partikel akan ikut terseret searah dengan arah rotasi bintang neutron.

2. Laju presesi seretan kerangka inersial $\Omega_{L T}$ di dalam bintang neutron yang stasioner dan simetri sumbu telah dirumuskan sebagai berikut $\Omega_{L T}=$

$\frac{e^{-(\alpha+\sigma)}}{2\left(\omega^{2} r^{2} \sin ^{2} \theta-e^{2 \sigma}\right)}\left[\left[\omega^{2} \omega_{, \theta} r^{2} \sin ^{3} \theta+\right.\right.$ $e^{2 \sigma}\left(\omega_{, \theta} \sin \theta+2 \omega \cos \theta-\right.$ $\left.\left.2 \sigma_{, \theta} \omega \sin \theta\right)\right]^{2}+\sin ^{2} \theta\left[\omega^{2} \omega_{, r} r^{3} \sin ^{2} \theta+\right.$ $\left.\left.e^{2 \sigma}\left(2 \omega+r \omega_{, r}-2 \omega r \sigma_{, r}\right)\right]^{2}\right]^{1 / 2}$

dengan $\gamma, \sigma . \alpha$, dan $\omega$ adalah fungsi yang hanya bergantung pada $r$ dan $\theta$ dan $\omega$ adalah kecepatan rotasi bintang neutron. Pada pusat bintang, yaitu saat $r=0$, laju presesi Lense Thirring menjadi

$$
\left.\Omega_{L T}\right|_{r=0}=\left.\omega e^{-(\alpha+\sigma)}\right|_{r=0} .
$$

Laju presesi seretan kerangka sebanding dengan kecepatan sudut bintang dan berbanding terbalik dengan jari-jari bintang. Semakin besar $r$, maka efek seretan kerangka semakin mengecil.

\section{DAFTAR PUSTAKA}

Arny, T. dan Schneider, S. G., 2014, Explorations: An Introduction to Astronomy, $7^{\text {th }}$ Edition, New York: McGraw Hill Companies

Carroll, S., 2004, Spacetime And Geometry: An Introduction to General relativity, San Francisco: Addison Wesley

Chakraborty, C. dan Majumdar, P., 2014, Strong gravity Lense-Thirring Precession in Kerr and Kerr-Taub-NUT arXiv: 1304.6936v2[gr-qc].

Chakraborty, C., Modak, P. K., dan Bandyopadhyay, D., 2014, Dragging of Inertial frames inside the Rotating Neutron Stars, arXiv: 1402.6108v2astro-ph.HE.

Glendenning, N. K. dan Weber, F., 1994, Impact of frame dragging on the Keplerfrequency of relativistic stars, Phys. Rev. D50, 3836.

Glendenning, N. K., 2000, Compact Stars: Nuclear Physics, Particle Physics, and General relativity, $2^{\text {nd }}$ Edition, California: Springer

Hackmann, E., dan Lammerzahl, C., 2012, Phys. Rev.D, 85, 044049

Haensel, P., Potekhin, A. Y., dan Yakovlev, D. E., 2007, Neutron Stars I: Equation of State and Structure, New York: Springer 
Hobson, M. P., Efstathlou, G., dan Lasenby, A. N., 2006, General Relativity: An Introduction for Physicists, UK: Cambridge University Press

Hartle, J. B., 1967, Slowly Rotating Relativistic Stars I. Equation of Structure, The Astrophysical Journal, Vol. 150.

Hartle, J. B. dan Thorne, K. S., 1968, Slowly Rotating Relativistic Stars II. Models for Neutron Stars and Supermassive Stars, The Astrophysical Journal, Vol. 153.

Hartle, J. B., 2009, Gravity: An Introduction to Einstein's General relativity, San Francisco: Addison Wesley

Iorio, L., 2011, Astrophys Space Sci, 331: 351395

Komatsu, H., Eriguchi, Y., dan Hachisu, I., 1989, Rapidly rotating general relativisticstars- $I$. Numerical method and its application to uniformly rotating polytropes, Mon. Not. R. astr. Soc. (1989)237,355-379.
Lense, J. dan Thirring, H., 1918, Über den Einfluss der Eigenrotation der Zentralkörper auf die Bewegung der Planeten und Monde nach der Einsteinschen Gravitationstheorie, Phys. Z 19, 156-163.

Morsink, S. M., Stella, 1., dan Vietri, M., 1999, Correlation in the Quasi-periodic Oscillation Frequencies of Low-mass X-ray Binaries and The Relativistic Precession Model, The Astrophysical Journal, 524:L63-L66.

Shapiro, S. L. dan Teulolsky, S. A., 2004, Black Hole, White Dwarfs, and Neutron Stars, Germany: WILEY-VCH

Strauman, N., 2004, General Relativity with Applications to Astrophysics, New York: Springer

Weber, F., Negreiros, R., Rosenfield, P., dan Stejner, M., 2006, Pulsars as Astrophysical Laboratories for Nuclear and Particle Physics, arXiv:astro-ph/0612054v1. 